\title{
O QUADRO EUROPEU DE BOAS PRÁTICAS DE LITERACIA
}

\author{
David Mallows (UCL - Institute of Education, United Kingdom)*
}

\section{RESUMO}

Neste artigo, introduzo um Quadro de Referência de Boas Práticas desenvolvido pela Rede Europeia de Políticas de Literacia (ELINET) financiada pela Comissão Europeia. O quadro aborda as políticas de literacia em todo o ciclo de vida, mas aqui concentro-me apenas em questões relevantes para a educação de adultos. O Quadro está organizado em três tópicos oriundos das recomendações feitas pelo Grupo de Alto Nível da União Europeia sobre literacia, em 2012: criar ambientes mais alfabetizados; melhorar a qualidade do ensino; e aumentar a participação e a inclusão.

Palavras Chave: Literacia. Adultos. Políticas públicas. Europa.

\section{ABSTRACT}

\section{THE EUROPEAN FRAMEWORK OF LITERACY GOOD PRACTICE}

In this article, I introduce the European Framework of Good Practice developed by the European Literacy Policy Network (ELINET) financed by the European Union. The Framework considers literacy policies for all cycles of life, but for this purpose I only focus relevant issues for adult education. The Framework is organised around three topics defined from the recommendations made by the EU High Level Group of Experts on Literacy, in 2012: the creation of more literate environments; the improvement of the quality of teaching; and increasing participation and inclusion.

Keywords: Literacy. Adults. Public policies. Europe.

\section{RESUMEN}

\section{EL CUADRO EUROPEO DE BUENAS PRÁCTICAS DE ALFABETIZACIÓN}

En este artículo, introduco el Marco de Referencia de Buenas Prácticas desarrollado por la Red Europea de Políticas de Alfabetización (ELINET) fi-

* David Mallows é Principal Teaching Fellow no Institute of Education da University College London, Reino Unido. Tem mais de 30 anos de experiência como professor, formador, gestor e investigador em Educação de Adultos. Ensinou Inglês em Espanha, Brasil, França e Suíça antes de começar a trabalhar com emigrantes e refugiados em Inglaterra. Foi até 2016 diretor de Investigação no National Research and Development Centre for adult literacy and numeracy (NRDC). No projeto ELINET (EU, 2013-2106), coordenou a equipa de investigação sobre políticas e práticas de literacia para Adultos. Na plataforma EPALE - Electronic Platform for Adult Learning in Europe coordena a temática das Competências para a Vida (Life Skills).E-mail: d.mallows@ucl.ac.uk 
nanciada por la Comisión Europea. El marco aborda las políticas de alfabetización en todo el ciclo de vida, pero aquí me concentro sólo en cuestiones relevantes para la educación de adultos. El cuadro está organizado en tres temas derivados de las recomendaciones del Grupo de Alto Nivel de la Unión Europea sobre alfabetización en 2012: crear entornos más alfabetizados; mejorar la calidad de la enseñanza; y aumentar la participación y la inclusión.

Palabras Clave: Alfabetización. Adultos. Políticas públicas. Europa.

\section{Introdução}

A literacia é fundamental para o desenvolvimento humano. Permite que as pessoas tenham uma vida plena e significativa e contribuam para o enriquecimento das comunidades em que todos vivemos. Por literacia entendemos a capacidade de ler e escrever em um nível em que os indivíduos possam efetivamente entender e usar a comunicação escrita, seja em mídia impressa ou digital. A literacia, assim entendida, é um pré-requisito essencial para todas as formas de aprendizagem. Nas sociedades baseadas no conhecimento do século XXI, com a rápida disseminação de novas tecnologias e um ambiente de trabalho em constante mudança, a literacia não se limita mais à escola, mas deve ser reconhecida como uma necessidade e um requisito para toda a vida.

\section{O desafio europeu da literacia}

$\mathrm{Na}$ Europa, um em cada cinco jovens de 15 anos e quase 55 milhões de adultos não possuem habilidades básicas de literacia. Isto aumenta o risco de pobreza e exclusão social, limitando as oportunidades de emprego, a participação cultural e civil, a aprendizagem ao longo da vida, e o crescimento pessoal. A Comissão Europeia reconhece que, desde os resultados alarmantes do primeiro estudo do PISA (OCDE, 2001), houve pouca melhoria neste domínio da literacia. No entanto, acredita que com o apoio certo, crianças, jovens e adultos podem desenvolver as habilidades de literacia de que precisam para trabalhar de forma eficaz e independente na sociedade.

Neste contexto, a Rede Europeia de Políticas de Literacia - ELINET, foi criada pela Comissão Europeia em fevereiro de 2014 para completar um ambicioso programa de trabalho de dois anos. A ELINET foi constituída por 78 membros de 28 países europeus, representando uma ampla gama de atores no campo da alfabetização e da literacia: redes de alfabetização e de literacia, ministérios da educação, agências nacionais, organizações transnacionais e internacionais, fundações, ONGs, universidades, centros de pesquisa, instituições de formação de professores, organizações voluntárias e outros grupos de partes interessadas. A ELINET reuniu pesquisadores, profissionais, profissionais e voluntários que trabalham em todas as faixas etárias e setores, cobrindo a literacia familiar, crianças dos níveis pré-escolar e primário, adolescentes e adultos; aprendizagem informal, não formal e formal; literacia digital, leitura por prazer e muito mais.

Um dos principais resultados do projeto ELINET foi o Quadro Europeu de Boas Práticas para aumentar os níveis de literacia de crianças, adolescentes e adultos. Esta foi uma tentativa de descrever boas práticas nas políticas de literacia europeias. Segue diretamente as conclusões do relatório final do grupo de especialistas de alto nível da União Europeia (UE) sobre literacia - High Level 
Group of Experts on Literacy (EU-HLGEL, 2012) que foi estabelecido pela Comissão Europeia para estudar como apoiar o desenvolvimento da litercia ao longo da vida nos países europeus. Neste Relatório Final, os especialistas concluíram que, para os Estados-Membros da UE encontrarem as formas mais eficientes e eficazes de responder às necessidades de literacia de todos os seus cidadãos, há três questões fundamentais que todos devem considerar:

- Criar ambientes mais alfabetizados

- Melhorar a qualidade do ensino

- Aumentar a participação e inclusão

Neste artigo, descrevem-se os elementos do Quadro Europeu de Boas Práticas que são relevantes para a literacia de adultos, sob estes três tópicos.

\section{Criar ambientes mais alfabetizados}

Nas sociedades contemporâneas, as demandas pela alfabetização e a literacia estão se tornando cada vez mais complexas para todos, em todos os setores da vida privada e pública. Crianças, jovens e adultos precisam, portanto, de um "ambiente letrado" rico e inspirador, a fim de desenvolver as habilidades e atitudes necessárias para lidar com essas demandas de alfabetização cada vez mais complexas.

Num ambiente rico e letrado, livros e outros materiais de leitura, impressos ou digitais, estão facilmente disponíveis em casa, em escolas, bibliotecas e para além delas. A motivação e o apoio ao 'engajamento' com a literacia começam na família e nas instituições pré-escolares. Escolas e bibliotecas públicas oferecem programas inspiradores e oportunidades para os alunos acessarem materiais de leitura atraentes e se envolverem em leitura e escrita por prazer.
As habilidades e práticas de leitura e escrita dos adultos respondem e são moldadas pelas exigências de leitura e escrita de qualquer domínio específico e pelo tipo de apoio que recebem para melhorar seus níveis de literacia. Nesse sentido, deve-se considerar as oportunidades de literacia e apoio disponíveis para os adultos em todas as áreas de suas vidas. É importante oferecer uma ampla gama de oportunidades de leitura e redação para que os adultos estejam habilitados e motivados a usar as suas competências de literacia e o seu conhecimento em muitos domínios das suas vidas: por prazer, lazer, trabalho e outros fins práticos. Como os adultos lêem em muitos domínios, fica claro que o ambiente letrado envolve diferentes instituições, sendo, por isso, de grande importância, a cooperação sistemática entre os formuladores de políticas.

Os adultos envolvem-se com textos escritos no local de trabalho e no domicílio, quando acessam os serviços governamentais e atendem às demandas institucionais, quando usam os serviços de transporte público e de saúde, quando lidam com as escolas de seus filhos e, claro, através da comercialização de bens e serviços que geram uma grande parte do escrito que os adultos encontram. Envolvem-se também em leitura por prazer e para uma compreensão mais ampla de si mesmos e do mundo em que vivem. Os textos que lêem podem estar impressos ou em tela, com os textos digitais representando uma proporção crescente dos textos disponíveis. A consideração dos usos de textos escritos em cada um desses domínios, tanto impressos quanto digitais, é vital para a criação de um ambiente letrado positivo.

Por tudo isto, um ambiente alfabetizado positivo é aquele em que:

- os adultos são encorajados e apoia- 
dos no 'engajamento' com material escrito;

- há cuidado, nos locais de trabalho e em outros espaços públicos, em garantir que a comunicação escrita é acessível e que os trabalhadores são apoiados no uso de leitura e escrita como parte de suas práticas laborais;

- são acordadas directrizes sobre a clareza da comunicação escrita e essas são seguidas por organizações, públicas e privadas, que se envolvem por escrito com o público;

- se identificam exemplos de má comunicação escrita, se oferece apoio quando necessário, e as boas práticas são promovidas e celebradas;

- há campanhas de comunicação nacionais para aumentar a consciência sobre questões relacionadas com a alfabetização e literacia dos adultos, contribuindo também para a desestigmatização das pessoas;

- os adultos com baixos níveis de leitura e escrita são encorajados a participar em programas flexíveis de literacia;

- existe uma infra-estrutura nacional abrangente e coerente para a alfabetização e a literacia de adultos;

- ler e escrever por prazer são promovidos e celebrados como de importância central para a cultura nacional;

- existe uma cultura vibrante e variada de publicações nacionais e locais e uma rede de bibliotecas públicas com bons recursos que são acessíveis por transporte público.

\section{Melhorar a qualidade do ensino}

"O acesso à educação significa pouco sem provisão de alta qualidade e apoio especia- lizado direcionado àqueles que mais precisam."

(EU-HLGEL, 2012, p. 46)

A qualidade do ensino é um fator determinante do sucesso educacional. Para a melhorar é necessário considerar aspectos como: currículos coerentes de literacia, literacia de alta qualidade, professores bem qualificados e material impresso e digital criativo e coerente. Nestes ambientes de qualidade reconhece-se a necessidade de diagnóstico e de avaliações regulares para identificar adultos em dificuldades, a fim de apoiar aqueles com dificuldades neste domínio. Na oferta de programas para adultos, o diagnóstico é rigoroso de modo a colocar os alunos na oferta apropriada e a avaliação contínua para monitorar seu progresso é de grande importância.

A oferta de educação de adultos no âmbito da literacia inclui tanto aulas formais como não formais bem como outras oportunidades de aprendizado destinadas a melhorar as habilidades de leitura e escrita de adultos. Ao descrever o sistema de educação em literacia para adultos, devemos considerar o espectro mais amplo possível de oportunidades disponíveis e entender que é necessária uma grande diversidade de entidades e tipos de oferta. Estas ofertas podem assumir a forma de cursos formais conducentes à acreditação, mas podem igualmente ser não formais, com o objetivo principal de estimular a confiança e envolver adultos que, por um lado, possam ter tido experiências anteriores negativas de aprendizagem e ou, por outro lado, para quem um curso formal é inadequado. Tal oferta não-formal pode ser concretizada em aulas com um professor, mas também pode, por exemplo, tomar a forma de um círculo de leitura ou de apoio individual numa oficina. 
Tal provisão de formação deve ser relevante para uma grande variedade de aprendizes adultos. Deverá ser abrangente, eliminando barreiras para grupos desfavorecidos ou marginalizados e deve abranger todos os domínios da vida adulta, incluindo a vida familiar, o trabalho, o lazer; deve também sustentar a aprendizagem ao longo da vida numa abordagem sectorial e intersectorial,. Vejam-se, por exemplo, o EU-HLGEL (2012, p. 93) e o relatório do UNESCO Institute for Lifelong Learning (UIL) (2010, p. 7). A literacia de adultos deve estar inserida no cotidiano da vida adulta, nos locais de trabalho, na comunidade, no lar e em outras arenas da vida familiar (EU-HLGEL, 2012, p. 93).

A oferta de literacia na educação de adultos deve ser acessível a todos os alunos, independentemente dos seus meios financeiros, e os adultos devem receber orientação apropriada sobre como aceder a essas oportunidades educacionais. Além disso, essa oferta deve dar aos alunos a oportunidade de continuar os seus percursos educacionais ao longo de toda a vida (UIL, 2013, p. 35), oferecendo caminhos para outras formas de educação, seja acadêmica, profissional ou por prazer e crescimento pessoal. As características de boas práticas neste âmbito, são as seguintes:

As comunidades locais devem ser obrigadas e apoiadas pelo governo nacional a abrir centros de alfabetização e literacia para adultos. Os potenciais alunos devem ser ativamente motivados e apoiados para (re)entrar na aprendizagem. O sucesso nessa aprendizagem deve ser destacado e promovido pela mídia nacional e local.

A acessibilidade é um fator chave. A participação deve ser gratuita e todos os alunos, independentemente do sexo, idade ou etnia, devem ser bem-vindos. O local de aprendi- zagem deve ser de fácil acesso para o aluno e a formação deve ocorrer em horários convenientes, que reconheçam que os adultos têm outras demandas em suas vidas.

Os objetivos de aprendizagem em tais programas devem ser claros e responder às necessidades dos aprendentes, a qualidade do ensino deve ser assegurada e os alunos e professores devem demonstrar respeito pelas diferentes convicções políticas e/ou religiosas.

O ensino de literacia de adultos de alta qualidade é flexível, levando em conta as circunstâncias específicas do aluno e de seu ambiente; deve ser ministrado por profissionais de literacia de adultos bem qualificados e bem apoiados; está organizado em torno de uma estrutura curricular nacional que apóia todo o espectro de alfabetizadores de adultos; a sua qualidade é assegurada por meio de um sistema de monitoramento e avaliação vinculado a padrões nacionais; para além disso, é informado por pesquisas regulares, conduzidas para avaliar as necessidades dos adultos em literacia e os níveis de oferta.

\section{Programas que promovem a literacia digital e habilidades de multi-literacia}

O grupo de peritos em literacia da UE destacou, ainda, o facto de que, na Europa, a lacuna digital afeta um número crescente de adultos. Dado que a utilização de media digitais por alunos adultos após formação adequada pode ajudar a manter e melhorar as suas competências em literacia, o grupo recomendou a utilização de práticas digitais na educação e aprendizagem, tanto dentro como fora da sala de aula, bem como medidas específicas visando o fechamento do gap digital. Para além disso, as políticas que 
regulam o acesso e o uso de mídia digital e as políticas de educação e de alfabetização de adultos estão vinculadas nesse sentido. É necessário um planejamento cuidadoso para garantir que nenhum grupo seja excluído de experimentar a variedade de práticas digitais e para examinar se as instâncias de exclusão são motivadas principalmente pela falta de habilidades/conhecimentos, falta de interesse/envolvimento em certas práticas de vida, por questões de alfabetização ou financeiras (ou seja, alguém pode ter as habilidades para usar um laptop, mas pode não ser capaz de o pagar).

Existem três razões importantes para incorporar a tecnologia digital em estratégias para o desenvolvimento da literacia de adultos. Em primeiro lugar, muitos adultos agora se engajam em práticas de literacia on-line e, portanto, qualquer iniciativa neste campo que não incorpore recursos tecnológicos não capacitará os adultos com as habilidades e o conhecimento necessário para responder às demandas impostas por seus ambientes de literacia pessoais. Em segundo lugar, os adultos geralmente têm uma vida ocupada com pouco tempo de sobra para participar de programas formais ou não formais de literacia. A tecnologia pode facilitar o seu envolvimento, disponibilizando recursos de aprendizagem e suporte que os adultos podem acessar quando e onde tiverem tempo. Em terceiro lugar, a tecnologia oferece a possibilidade de incluir recursos multimídia e interativos que podem tornar o desenvolvimento em literacia mais atraente e realista, incentivando e até mesmo inspirando os adultos a desenvolver as suas práticas de leitura e escrita.

A tecnologia pode ainda ser usada para ministrar parte de um programa de formação em combinação com a formação presencial tradicional (aprendizagem combinada) ou apenas para fornecer formação on-line autônoma. Em alguns casos, pode permitir uma expansão da oferta com vantagens económicas.

\section{Currículos de literacia na educação de adultos}

Nestas boas práticas, distingue-se entre uma estrutura curricular que descreve a abordagem geral à literacia para adultos, mas não especifica o conteúdo dos programas, e um currículo que especifica o conteúdo específico de tais cursos. Ambos são elementos importantes de qualquer política de alfabetização válida e fornecem suporte valioso para os profissionais que trabalham a literacia com adultos.

Uma boa oferta de literacia para adultos responde às necessidades destes sujeitos e das suas vidase, embora no currículo possam ser especificados possíveis conteúdos em termos de habilidades e conhecimentos, ele deve ser usado pelos profissionais mais como um guia do que como prescrição.

São várias as características das boas práticas nesta área que podem ser identificadas. O currículo de literacia para a educação de adultos considera a heterogeneidade de ambientes educacionais nos quais a oferta de formação ocorre, tal como as variadas necessidades de aprendizagem dos participantes. Do ponto de vista da aprendizagem ao longo da vida, esse currículo deve concentrar-se em atividades relevantes para este público. O Manifesto Eur-Alpha, desenvolvido por um grupo transnacional de alfabetizadores de adultos (Eur-Alpha 2011, p. 6), lista alguns deles: lidar com tarefas administrativas, Tecnologias de Informação e Comunicação (TICs), educação, viagens, segurança, trabalho e direitos civis. 
Ao desenvolver um currículo de literacia para adultos, deve-se pensar na amplitude que o significado de literacia assume ou envolve para diferentes adultos e na sempre presente questão sobre quem ou o quê determina esses currículos e quem decide sobre o que é relevante para os adultos e suas vidas.

Nos casos de sucesso, o currículo assenta em normas que identificam a gama de habilidades e capacidades de leitura e escrita que os adultos precisam para funcionar e progredir no trabalho e na sociedade, o que deve ser verificado e confirmado por observação direta. Tais normas constituem a base da qualificação nacional de professores para a educação de adultos em literacia e o currículo especifica o que os professores devem ensinar para permitir que os alunos alcancem essas metas em cada nível e relativamente a todas as habilidades de leitura e escrita.

O currículo e as normas nas quais se baseia devem abranger as habilidades de leitura e escrita e descrever o conteúdo requerido em cada nível relevante da palavra, frase e texto. Deve apoiar os profissionais no desenvolvimento de avaliações diagnósticas para identificar as habilidades e conhecimentos prévios dos alunos, bem como aqueles que eles precisam desenvolver como parte de seu programa de aprendizagem. Deve também reconhecer que existem muitas maneiras de ensinar a literacia de adultos. Os formadores devem ter a oportunidade de aprender sobre isso formalmente através de programas de formação específicos e informalmente por meio do envolvimento com outros profissionais. Finalmente, o treino deve estar disponível para todos os envolvidos na oferta de alfabetização de adultos e deve ser desenvolvido e fornecido como parte do desenvolvimento de um currículo de literacia para adultos.

\section{Identificar as necessidades de literacia dos adultos}

Dados do PIAAC (Programme for the International Assessment of Adult Competencies), a par de outros estudos, sugerem que 1 em cada 5 adultos, nas nossas sociedades, possuem baixos níveis de literacia. No entanto, apenas uma pequena proporção deles está envolvida em programas formais de literacia, onde poderão beneficiar de processos de avaliação formativa e somativa.

Entendemos a literacia como um leque de competências organizadas num sistema binário de alfabetizado/analfabeto. Consequentemente, não falamos de adultos "analfabetos" - todos têm um grau de conhecimento das práticas de leitura e escrita nos seus contextos sociais e, portanto, todos, em certa medida, são alfabetizados. No entanto, os adultos com baixos níveis de literacia sentem-se envergonhados por acharem difícil ler e escrever. Simplesmente, podem ter tido experiências negativas com a educação e/ou podem ser vulneráveis na medida em que pertencem a grupos minoritários ou marginalizados.

As habilidades e o conhecimento de literacia integram, naturalmente, o repertório linguístico das pessoas, o que, nas sociedades multilingues e multiculturais atuais, pode ser diverso e múltiplo. Por exemplo, adultos com baixos níveis de literacia na língua oficial do seu local de residência podem ser alfabetizados em um ou mais idiomas, ou podem até usar uma grande variedade de idiomas oficiais que não o da “norma padrão".

A fim de desenhar programas educacionais apropriados, é importante compreender, profundamente as habilidades e práticas de literacia dos adultos; devem ser reconhecidos os seus conhecimentos prévios e identificadas as suas motivações e neces- 
sidades de aprendizagem. Neste processo, é de suma importância que os alunos adultos sejam tratados com respeito. No contexto de adultos, antes do trabalho do professor/formador, o diagnóstico, a avaliação e o apoio devem ser distintos e antecedidos de uma fase preliminar de identificação das necessidades de literacia e o encaminhamento para a oferta adequada. Um candidato pode, então, realizar uma avaliação inicial para ser colocado na formação apropriada e uma avaliação formativa contínua, à medida que prossiga na aprendizagem da literacia.

Para os adultos, reconhecer que têm necessidades de leitura e escrita e engajar-se com a literacia é, frequentemente, um passo difícil e pode exigir ação e incentivo de vários atores e agências diferentes. Aqui, distinguimos Sinalização/Referência e Rastreio, mas na realidade estas duas fases podem ser fundidas ou, até mesmo, os alunos podem ser encaminhados diretamente para a oferta de aprendizagem para avaliação inicial sem a necessidade de rastreio.

Com vista a boas práticas, informação sobre a oferta de formação neste âmbito da literacia de adultos deve ser amplamente disponibilizada por meio de campanhas públicas de divulgação. Atores das áreas da saúde, emprego, habitação junto com outros funcionários do governo local, regional e nacional, bem como ONGs que tenham contacto regular com as populações devem receber formação para identificar sinais de alfabetização precária e para saber como e para onde encaminhar potenciais aprendizes. Os provedores de ensino e formação devem trabalhar de forma proativa com organizações que mantêm contato regular com o público em geral para aumentar a consciência sobre oportunidades de aprendizagem de literacia a nível local e estabelecer processos simples de encaminhamento. A 'triagem' envolve a realização de um pequeno conjunto de tarefas de literacia autênticas para determinar se o adulto tem necessidades de formação. Para tal, os provedores de ensino e formação, os serviços de emprego, os empregadores e outros devem ter disponíveis processos para avaliar essas necessidades. Tais processos devem ser privados, confidenciais e relaizados em ambientes 'amigáveis' e de apoio. Por isto, é importante que aqueles que realizam a 'triagem' recebam formação adequada e estejam cientes da natureza sensível da avaliação destas habilidades. Esta avaliação inicial deve incluir uma entrevista para permitir que a instituição de educação e formação compreenda toda a gama de necessidades de aprendizagem do indivíduo, bem como quaisquer problemas familiares, de trabalho ou de saúde que possam afetar a aprendizagem.

\section{Aumentar a participação, inclusão e equidade}

Como demonstram as avaliações internacionais sobre literacia, como o PIAAC já referido, o PIRLS (Progress in International Reading Literacy Study) e o PISA (Programme for International Student Assessment ), em todos os países europeus existem, em maior ou menor grau, disparidades no desempenho em literacia entre os diferentes grupos. Particularmente preocupantes, pelas disparidades que geram neste âmbito, são as barreiras sociais e a questão dos migrantes. Fechar ou reduzir significativamente essas diferenças são alguns dos maiores desafios da literacia na Europa. Com efeito, toda a oferta de literacia para a população adulta visa eliminar essas barreiras, apoiando os adultos a adquirir as habilidades de leitura e escrita de que necessitam e sem as quais podem estar em risco de não responder às 
exigências que lhes são impostas como cidadãos, funcionários e mesmo na família.

Os decisores políticos têm já à sua disposição uma grande quantidade de informações, que podem extrair do PIAAC e de outros estudos, para identificar grupos de adultos com maior probabilidade de terem baixos níveis de literacia. Estas informações podem ser usadas para conceber e orientar campanhas de sensibilização e ofertas educativas. Entretanto, os formuladores de políticas também devem estar cientes de que, embora seja grande a probabilidade de os adultos com baixa proficiência em literacia apresentarem certas características relativamente ao restante da população adulta (por exemplo, não conclusão do ensino médio, emprego pouco qualificado, falta de participação em assuntos cívicos, etc.), a maioria deles não. Muitos adultos com baixos níveis de literacia são cidadãos bem-sucedidos, funcionários e membros de família, mas que, apesar disso, beneficiariam da melhoria das suas práticas de literacia. No entanto, com fundos públicos limitados para apoiar a oferta de literacia a adultos, compreende-se que esses escassos recursos sejam direcionados aos mais necessitados.

É uma questão de importância nacional que todos os cidadãos e residentes compreendam e sejam capazes de comunicar adequadamente na língua ou línguas nacionais. Quando a língua oficial de um país é a segunda ou terceira língua de um adulto, e esse adulto ainda está a adquirir o domínio desta língua oficial, o conhecimento dos métodos de ensino e aprendizagem da segunda língua, da língua estrangeira, do bilinguismo deve informar o design do currículo dos programas de ensino e aprendizagem. No entanto, ao projetar tal oferta, é importante ter em mente que esses adultos são obrigados a aprender tanto a comunicação oral quanto a escrita. Alunos que já possuem habilidades de literacia de nível superior nas suas línguas maternas terão necessidades diferentes daqueles que possuem pouca ou nenhuma habilidade. Também é importante considerar as necessidades de aprendizagem daqueles que usam uma variedade não -padrão da língua nacional (por exemplo, uma variedade de francês caribenho), que pode diferir da variedade nacional "padrão" em vocabulário, gramática e ortografia.

Assim, os formuladores de políticas bem como outros agentes precisam conhecer bem que grupos dentro das suas comunidades apresentam maior probabilidade de ter habilidades de literacia frágeis, de modo que a oferta educativa possa ser direcionada para esses grupos identificados como de maior risco. Campanhas de consciencialização podem, então, destacar o benefício para os indivíduos de práticas de literacia mais desenvolvidas. Tais campanhas devem usar modelos para incentivar todos os adultos que apresentam risco de não se envolver.

\section{Conclusão}

O Quadro Europeu de Boas Práticas exige dos formuladores de políticas atenção, e ação cuidadosa, a fim de se formularem políticas de literacia nacionais, regionais e locais que permitam que as pessoas tenham uma vida plena e significativa e contribuam para o enriquecimento das comunidades em que todos vivemos. A literacia e a aprendizagem são questões relevantes em todos os setores do estado e requerem, por isso, a promoção sistemática de ações políticas que se reforcem mutuamente nos departamentos e agências do governo, bem como numa ampla gama de atores políticos.

A Europa e seus Estados-Membros deveriam posicionar a literacia não apenas no 
cerne das suas estratégias educacionais, mas também no centro das políticas públicas em geral (HLG, 2012, p. 31).

A coerência das políticas de literacia só pode ser alcançada quando se compreende o grande impacto da leitura e da escrita numa ampla gama de áreas políticas, além da educação, como saúde e emprego, entre outras. Na verdade, quando, cada vez mais, os governos se envolvem on-line com seus cidadãos, nenhuma área governamental pode dar-se ao luxo de desconhecer a literacia como uma questão de importância individual, regional, nacional e global. Nos departamentos e agências governamentais, os decisores políticos devem olhar para além de suas próprias áreas estreitas de responsabilidade e buscar ativamente maneiras de explorar impactos positivos para lá da sua própria esfera política, apoiando o desenvolvimento de políticas e programas que busquem entender as necessidades de literacia dos cidadãos europeus bem como apoiando-os no cumprimento dessas exigências. Essa coerência política só pode ser alcançada quando há clareza nas políticas em curso: como elas são enquadradas, quem são os atores e que instrumentos políticos pretendem usar.

Frequentemente, as políticas não são coerentes porque os vários intervenientes não têm uma compreensão partilhada sobre o fenómeno. A constante mudança e rotatividade das políticas não funciona a favor da coerência, exigindo constante renegociação e recalibração. Essa constante mudança também reduz inevitavelmente a memória institucional, o que significa que qualquer nova política não é necessariamente informada pelo que ocorreu antes. A cooperação eficaz entre todas as partes interessadas é fundamental e, para isso, tais partes precisam ter bem presente quais são suas próprias responsabilidades e o que podem ganhar, para além, claro, da necessidade de haver confiança entre elas. A confiança constrói-se através de trabalho conjunto bem-sucedido, apoiando o aumento de conhecimento e compreensão compartilhados.

Embora a literacia, como já visto, seja uma questão a ser tratada por vários ministérios em diferentes áreas do governo, os formuladores de políticas de educação são centrais no desenvolvimento de políticas neste campo. A fim de assegurar que as políticas e os programas atraiam os adultos e atendam às suas necessidades e possibilidades, esses agentes de política de educação em literacia devem também garantir que os próprios adultos possam ter um papel importante na elaboração dessas políticas e práticas. Isso permitiria que a política de literacia fosse informada pela compreensão das exigências que a literacia coloca a todos nós no engajamento efetivo com a sociedade.

A ELINET teve como objetivo melhorar as políticas de literacia nos países membros, a fim de reduzir o número de crianças, jovens e adultos com baixas competências de leitura e escrita. O objetivo ambicioso que inspirou todo o trabalho da ELINET foi formulado na Declaração Europeia do Direito à Literacia, que foi lançada na Conferência Europeia de Literacia, em Amesterdão, em janeiro de 2016:

Todos na Europa têm o direito de adquirir literacia. Os Estados-Membros da UE devem garantir que as pessoas de todas as idades, independentemente da classe social, religião, etnia, origem e sexo, disponham dos recursos e oportunidades necessários para desenvolver competências de literacia suficientes e sustentáveis para poderem compreender e utilizar eficazmente a comunicação escrita, na forma manuscrita, impressa ou digital. (ELINET, 2016) 
Para compreender o direito básico de todos os europeus de desenvolver a alfabetização, os formuladores de políticas em todo o governo, nos níveis europeu, nacional, regional e local devem garantir que todos os membros da sociedade estejam em condições de atender às demandas de alfabetização, seja como crianças, ou posteriormente, como adultos

\section{References}

ELINET, European Declaration of the Right to Literacy. 2016. Disponível em: http://www.eli-net.eu/about-us/literacy-declaration/. Acesso em 15 de novembro de 2018. What do we consider as "Good Practice"? 2016. Disponível em: http://www.eli-net.eu/good-practice/europeanframeworkofgoodpractice/. Acesso em 15 de novembro de 2018.

The European Framework of

Good Practice. 2016. Disponível em: http:// www.eli-net.eu/fileadmin/ELINET/Redaktion/ user_upload/European_Framework_of_Good_ Practice1.pdf. Acesso em 15 de novembro de 2018.

EU High Level Group of Experts on Literacy. Final Report, September 2012. Luxembourg:
Publications Office of the European Union. Disponível em: http://ec.europa.eu/ education/policy/school/doc/literacy-report_en.pdf.

EUR-ALPHA. Manifesto. Voice of Writing and Reading Learners in Europe. 2011. Brussels. Disponível em: http://www.eur-alpha. eu/IMG/pdf/manifesto_ukbat2.pdf.

OECD. Nowledge and skills for life. First results of the OECD Programme for International Student Assessment (PISA 2000). Paris: OECD, 2001

OECD. Education at a glance. OECD Indicators. 2011. Disponível em: http://www.oecd. org/education/skills-beyond-school/48631582. pdf.

UNESCO Institute for Lifelong Learning (UIL). CONFINTEA VI: Belém Framework for Action: Harnessing the power and potential of adult learning and education for a viable future. 2010. Hamburg: UIL.

UNESCO Institute for Lifelong Learning (UIL).

Global Report on Adult Learning and Education. Rethinking Literacy. 2013. Hamburg: UIL. 